\title{
A Fulguração de Ana
}

\author{
Moacir Amâncio
}

\begin{abstract}
Resumo: Este artigo trata de questões de leitura do original da Bíblia Hebraica no primeiro capítulo de 1 Samuel e também dos problemas de tradução apresentados pelo texto a partir do uso de palavras-guia tomadas como produtoras de sentido.
\end{abstract}

Palavras chave: Samuel, Ana, Bíblia, Mulher, Tradução

\section{1}

Este exercício de leitura tem como ponto de partida a comparação feita por Erich Auerbach entre a épica grega e a Bíblia Hebraica e pode ser uma tentativa de aproximação literária ao texto bíblico, porém a partir dele mesmo, a base para uma leitura a ser construída, pois ela não se dá ao leitor ${ }^{1}$. É assim que se aprendeu a ver a Bíblia Hebraica depois de Auerbach, seguindo de resto o exemplo da leitura rabínica tradicional, onde as análises funcionam como uma espécie de romance em várias dimensões ao redor de enredos básicos. Desse modo os textos bíblicos se impõem. A principal diferença entre eles e a épica grega seria também determinada pelo objetivo de seus autores. Cada obra conforme as tendências da cultura geradora, configurando-a em suas especificidades. Os poemas de Homero são detalhados de forma a recriar para o leitor todo um universo de harmonias e tensões bem orquestradas onde se movimentam personagens unidimensionais. Além disso, o poema homérico dispensaria esforços interpretativos como os exigidos pela narrativa bíblica. Auerbach elege, como se sabe, o Canto 19 da Odisséia para fazer paralelo

1. A Cicatriz de Ulisses, em Mimesis, Perspectiva, SP, 1971 
com o episódio bíblico do Sacrifício de Isaac (Gênesis, 22). Diz Auerbach: "Os relatos das Sagradas Escrituras não procuram o nosso favor, como os de Homero, não nos lisonjeiam, para nos agradar e nos encantar - o que querem é dominarnos... Neles encarnam doutrina e promessa, indissoluvelmente fundidos nestes relatos; precisamente por isso eles têm um caráter recôndito e obscuro, eles contêm um segundo sentido, oculto". O nó da questão está no fato de que "o texto bíblico, a partir do seu próprio conteúdo, é carente de interpretação. Só podemos buscar as possíveis variantes se nós nos inserirmos no próprio mundo bíblico, "sentirmo-nos membros da sua estrutura histórico-universal"².

Para Auerbach, essa adesão ao universo bíblico se torna cada vez mais difícil. No entanto, mesmo quando o leitor não queira ou não faça parte desse mundo, ele pode, com instrumentos de leitura fornecidos pelo texto, como disse, tatear o campo de significados. E será difícil, desconfio, para esse suposto leitor "isento", deixar de ser envolvido pela épica bíblica de forma a se considerar parte daquilo tudo, muito mais próximo enfim do homem contemporâneo do que a épica de Homero, pois a Bíblia Hebraica reivindica a presentificação do texto. Elipses e outros recursos estilísticos aproximam a expressão do homem bíblico de aspectos da literatura contemporânea, quando não influenciada diretamente pelas Escrituras. O chamado Médio Oriente parece simplesmente ocidental. E a Antiguidade se aproxima sob uma lente forte.

Por isso também Franz Rosenzweig compara os leitores a ouvintes. A narrativa diz, "captura esses ouvintes que estão distantes dela numa rede de diálogo secreto que se estende através das Escrituras; transforma ouvintes distantes em colaboradores, numa conversação que sob a casca do seu passado épico se abre para eles numa presença anedótica total"3.

\section{2}

Em vez do Sacrifico de Isaac, a Akedá, escolhi o trecho inicial do livro 1 de Samuel, em que temos uma história inversa àquela. No episódio de Abraão e seu filho, vemos a aceitação pura e simples do pedido que lhe é feito a partir de Deus para imolar Isaac em holocausto. O patriarca cumpre sem titubear a determinação

2. Idem, p. 11

3. Scripture and Translation, Indiana University Press, 1994, p.142

120 Moacir Amâncio - A Fulguração de Ana 
que lhe é transmitida "diretamente" e vai em direção ao local de sacrifício para entregar a vida do filho a Deus. Isaac foi o fruto de vidas até então estéreis, é recebido como um milagre. Algo parecido ocorre com Ana. Ela mesma, vendo no filho, como Abraão, a suprema dádiva dos céus, promete doá-lo ao serviço sagrado para sempre. É um texto curto, o primeiro capítulo de Samuel. Tem apenas 28 versículos.

Tentarei esboçar alguns caminhos de interpretação a partir de sua montagem literária. A direção é dada aqui por Rosenzweig e o que diz, assim como esta leitura, sugere um debate sobre as traduções bíblicas - se comparadas ao original elas empobrecem no potencial de significados, devido a características do hebraico trabalhadas pelos redatores de modo tantas vezes insuspeitado. Diz Rosenzweig: "Em certas circunstâncias, sobretudo, uma história é construída ao redor de toda uma série de palavras similares ou formalmente vinculadas, ou de sentenças formuladas" que no conjunto fazem pensar nas "trocas" de uma conversa animada" ${ }^{\text {. Em }}$ cada história, um sentido a ser buscado nas correspondências. Quando Rosenzweig fala sobre palavras similares ou formalmente vinculadas, refere-se a Martin Buber e ao brilhante achado e uso da milá-manhá ${ }^{5}$.

Buber explica que por milá-manhá (a partir do alemão Leitwort, palavra-guia) entendem-se termos ou raízes que retornam, num ou mais textos, criando uma dinâmica de significados implícitos e que podem auxiliar o leitor atento pelos labirintos do Pardês ${ }^{6}$. Trechos que até então podiam parecer truncados se revelam sob essa ótica como pertencentes a uma rede verbal que tece o pano de fundo para a cena. Artifício bastante usado na literatura, sobretudo na poesia e presente na prosa poética de um Guimarães Rosa, por exemplo, aponta para o nível estético das Escrituras. Estamos diante de uma questão muito intrincada, menos para a leitura no original, mais quando se trata da tarefa de traduzir. Como Auerbach demonstra, a Bíblia Hebraica não procura convencer, ela se coloca como a Verdade, fugindo ao didatismo. É a fonte básica da interpretação.

As traduções correm o risco de trair a fonte ao aplicar uma ideologia que é alheia a essa fonte. As repetições, tão constantes na linguagem bíblica, revelam-se dessa maneira um dado de riqueza estilística e não o contrário, como tempos por

4. Idem, p. 133

5. Darcô shel Mikrá, Mossad Bialik, Jerusalém, 1964, p. 287-307.

6. Fórmula mnemônica da epistemologia rabínica, em hebraico PRDS: Pashut: sentido simples do texto; Remez, alusão; Darash, exegese; Sod, o oculto no texto. Pardês significa horto, paraíso. 
exemplo em português. O mesmo acontece em inglês, como relata Robert Alter: "A operação da Leitwort, naturalmente, não é tão clara na tradução como no original: Buber e Rosenzweig atingiram distâncias extremas na sua versão alemã, a fim de preservar todas as Leitwörter; infelizmente, muitas traduções inglesas modernas vão para o extremo oposto, traduzindo de modo constante a mesma palavra por algum termo inglês equivalente por causa da fluência e suposta precisão. No entanto, a repetição de palavras-guia é tão proeminente em muitas narrativas bíblicas que se pode, ainda, segui-las muito bem na tradução. " Reproduzir as palavras-guia é um jeito de manter ou pelo menos sugerir a intenção do texto original, com suas maneiras próprias.

No trecho em pauta, o primeiro capítulo de 1 Samuel, notamos diversos detalhes que podem ser surpreendentes. Nesses 28 versículos, a duração no tempo é dada pela ação. Começa com a apresentação de Elcana e termina com a entrega de seu filho e de Ana ao sacerdote Eli, em Shilo, conforme a promessa da mulher. É possível calcular quanto tempo transcorreu nesse período. Chama atenção a presença de quatro sinalizações do verbo, vaiehi, que, como é usual, abre aspectos da narrativa. Ferreira de Almeida traduz por Houve, assim como a Bíblia de Jerusalém - o verbo nessa forma vincula-se à passagem e continuidade do tempo, colocando outro sério problema para a tradução, ainda não resolvido. A letra vav, agregada a iehi (será), aqui, indica o passado e não o futuro ${ }^{8}$.

Vaiehi é a primeira indicação, que nos coloca dentro do estímulo e induz ao point da narrativa, seguindo Rosenzweig - um point puxa outro. O vaiehi inicial nos instala num fluxo de continuidade que será reforçado no versículo dois, quanto vem o segundo vaiehi, que também nos informa sobre o passado agindo sobre o presente, espécie de ricochete do vaiehi anterior. A questão aqui, o mote, é o pro-

7. The Art of Biblical Narrative, Basic Books, Nova York, 1981

8. Walter Rehfeld explica o processo da seguinte forma: "Por influência do vav, freqüentemente o perfeito, em vez de indicar o passado, expressa o futuro, e o imperfeito, ligado pelo vav consecutivum, em vez de apontar ao futuro, indicará o passado. Por este fato os gramáticos tradicionais chamavam-no vav hahipukh, vav conversivm que, por meio de um poder misterioso, mudava os tempos verbais e transformava o passado no futuro e inversamente. Somente no século XIX, ao se reconhecer o caráter aspectivo das flexões verbais do hebraico bíblico, reconheceu-se, também, a verdadeira função do Vav: expressar a seqüência temporal e lógica, independentemente da referência temporal no momento presente do falante. Assim o nome teve que ser mudado de Vav hahipukh, Vav Conversivum para Vav Haretsifut ou Vav Consecutivum. Em Tempo e Religião, Perspectiva, SP, 1988 , p. 135. No mesmo capítulo, Rehfeld assinala que o tempo presente, como o conhecemos, não existia no hebraico bíblico, sendo um acréscimo posterior ao idioma, sob influência de línguas indo-européias. 
blema da descendência, já sugerido na abertura: o nome de Elcana vem solenemente acompanhado de quatro dos seus antepassados. No total, há 22 nomes no texto (o alfabeto hebraico é composto por 22 consoantes) e a palavra shem (nome) surge duas vezes. Mas dois nomes se destacam. O da protagonista Ana, que vai dominar a cena, aparecendo antes de Penina, a outra mulher de Elcana, e o de Samuel (Shemuel, Samuel, associado ao de Shaul, Saul, que será ungido pelo primeiro). Ana (Hana) quer dizer Graça. No entanto, ela nos é apresentada como uma mulher profundamente desgraçada. Porque, embora amada por Elcana, é inferiorizada por Penina, que tem filhos, enquanto Deus tinha fechado o útero de Ana.

O nome da heroína contrasta, como já disse, com sua situação e esse contraste é reforçado pela sugestão de duplicidade do termo rehem, útero, matriz, mas que também pode ser lido como raham, piedoso, misericordioso - a Bíblia de Jerusalém traduz por útero, mas com sua intuição poética, João Ferreira de Almeida (16281691) prefere o termo madre, por si só uma expressão de amor (raham também significa amar) e piedade. Raham deve referir-se a Deus, criador tanto da fertilidade como da esterilidade, mas até então a piedade divina do Deus Rahum estava fechada para Ana (Hana, com a mesma raiz de Hanun de novo referindo-se a Deus, aquele que concede a graça - esses dois termos aparecem em seqüência no Êxodo, o que sugere relação com a história de Ana) e a ausência dessa misericórdia se manifesta também nos maus tratos de Penina, em sua impiedade. No final, Deus atenderá à súplica de Ana, que concebe. Ela assume então a sua condição de agraciada por Rahamana assim Deus é chamado no aramaico talmúdico - conforme previra Eli no versículo 16, que recebe os agradecimentos de Hana, Ana, esta sempre se comportando de maneira humilde, com a esperança de "encontrar graça nos olhos" do sacerdote.

O terceiro vaiehi está no versículo 4, acompanhado da indicação temporal (Vaiehi haiom). Aí se encerra a introdução geral para dar início à ação. No começo ficamos sabendo que todo ano Elcana oferecia sacrifício em Shilo. Agora, estamos na época do sacrifício. A cena que se desenrola é teatral, como todo o capítulo. O drama explode no momento em que Elcana oferece a porção única de comida a Ana, lembrando-lhe sem intenção aparente a sua condição humilhante de estéril. Ela se nega a comer e a pergunta de Elcana vem coberta por uma espécie de máscara da ingenuidade: "Ana, por que choras? E por que não comes? E por que está mal o teu coração? Não te sou eu melhor do que dez filhos? ${ }^{9}$ "

9. Ferreira de Almeida, v. 8. 
Alusões diretas à procriação, com o filho, ben, no singular, e no plural, masculino e feminino (bat), e sinônimos (zera anashim, semente dos homens, iêled, menino, naar, jovem) aparece 18 vezes no capítulo. Como se sabe, 18 é o número formado pelas letras hebraicas het e iud, o que também significa viver, ou vida. No versículo 16 existe a expressão bat-belial, sinônimo para mulher inútil, à toa, e que por isso não foi incluída na contagem anterior, contendo uma ênfase à consciência que a heroína tem de sua própria dignidade, tão insistentemente pisoteada, pois sua desgraça passa indiferente pelo mundo.

A dramaticidade do diálogo Ana-Elcana ressalta quando ficamos sabendo logo adiante que o filho dela, se vier, será entregue ao serviço sagrado. Outro equívoco a respeito de Ana é cometido por Eli, o sacerdote que, observando a mulher em prece desesperada e voz contida, pensa está bêbada, pois só os lábios dela se movem. Do jejum, Ana passa ao protesto envolvido pelo disfarce da queixa, expondo, depois de fazê-lo para Deus, sua alma a Eli. O trecho se encerra com a voz do narrador. Ele nos informa que Elcana a conheceu e ela enfim engravidou.

O quarto vaiehi inicia a conclusão do capítulo, o que parece comprovar o papel decisivo do verbo na construção do texto, disparando e dividindo a ação. Ficamos sabendo que Ana deu à luz um menino, o que foi festejado por Elcana. Ela desta vez, de novo época do sacrifício em Shilo (Silo), não vai com a família, pois pretende amamentar o filho Shemuel, que recebe o nome por ter sido pedido (shaul) a Deus. A Bíblia de Jerusalém acrescenta, Shemuel pode ser entendido como "o nome de Deus é El". Mas também deve-se levar em conta a intenção da personagem como tal: a partir dela, as variações. A palavra ishá, mulher, aparece sete vezes no texto, uma espécie de sinalização a ser decifrada.

\section{3}

Podemos começar a trabalhar as pistas: a graça concedida a Ana tem dupla direção. Se de um lado ressalta a mulher na narrativa; de outro, a mulher surge para confirmar a tradição patriarcal - podemos comparar a situação com a de Tamar, que se prostitui com Judá para obter a confirmação do levirato (Gênesis, 38). Mas ao contrário de Tamar, Ana só tem Deus para dialogar, na sua profunda solidão de mulher de fé. E é a Deus que se dirige e então recebe a resposta, guardada na fórmula rehem-Raham (forma única em hebraico, sem vogais, $\mathrm{rhm}$ ). No útero de Ana, em sua matriz, na madre, pela palavra, se dá o ato da graça, hen, pois ali está contido o princípio da Criação, na qual a palavra é o motor, dentro da tradição

124 Moacir Amâncio - A Fulguração de Ana 
hebraica. O não que ela deixa e a comprovação de sua fé estão no encaminhamento do filho ao sacerdote. Aí sim, sua fé suplanta as leis e costumes dos homens, pois entregará seu filho ao serviço divino, renuncia a ele. Mais uma vez, note-se o paralelo com a Akedá. Tendo a mulher por protagonista, o trecho se revela de qualquer modo mais feminino quando observamos que a palavra ishá (outro exemplo de milá-manhá) surge sete vezes (inclusive no plural, nashim), fazendo lembrar os dias da criação e o descanso sabático para celebrar o Criador. Isso contra cinco vezes o termo hebraico para homem, ish. O apuro de elaboração poética sofisticada está no fato de que não só as personagens vivem o conflito, mas as próprias palavras se confrontam, como peças de um jogo.

Um jogo por ser descoberto pelo leitor do texto original, já que mais uma vez se coloca a velha dúvida sobre a traduzibilidade de certos escritos, o que se agrava no caso, pois a aproximação só ocorre quando afastados os véus ideológicos. O rabino David Kimhi (Radak), que viveu na Provença, entre 1160 e talvez 1235, expressa nos comentários o seu espanto com o fato de não ter encontrado nenhuma alusão dos sábios anteriores à quebra da norma praticada por Ana, que oferece o filho como nazir, uma espécie de monge (V. 11: "E fez um voto, dizendo: Senhor dos Exércitos! Se benignamente atentares para a aflição da tua serva, e de mim te lembrares, e da tua serva não te esqueceres, mas à tua serva deres um filho homem, ao Senhor o darei todos os dias da sua vida, e sobre a sua cabeça não passará navalha.") O gesto seria restrito ao campo de decisão masculino. Radak deixa de observar que Ana age de maneira parecida com a mãe de Sansão (Juízes, 13), que devota o filho ao nazirato. Isso indicaria a dedicação como algo usual, embora depois a prática tenha sido proibida às mulheres. Deixando de lado a dúvida sobre a acuidade de Radak, não se pode ignorar a perplexidade que deixa aflorar. E essa perplexidade não é desprezível, pois nos devolve ao texto. Há questões em aberto, contas e fio de um colar impensável.

Como, por exemplo, procurar um entendimento a partir do texto bíblico, do contexto geral do Pentateuco, seguindo as palavras-guia em busca das contas ocultas daquele colar enigmático? Será preciso lembrarmos que os termos rahum e hanun, como Moisés se refere a Deus, numa exaltação, aparecem em seqüência na frase que é concluída pela palavra emet (verdade). Em Hana, temos que, no início, o Rahum e o Hanun estavam desligados: seu rehem não concebe, a graça não vem. Os termos só se unirão ao final, quando então se dá a verdade (emet) da concepção, da vida, quando piedade-beneficência (hessed) e verdade se unem. Entende-se também porque o nome Shemuel, como uma confirmação de que o nome de Deus é 
El - o filho de Hana é o dado da Divindidade e a esta deve retornar. Então podemos ler todo o versículo de Êxodo 34:6 como uma explicação da história de Hana: "Vaiaavor Adonai al panav vaikrá Adonai Adonai El rahum vehanun erech apaim verav hessed veemet" - "Passando, pois, o Senhor perante ele, clamou: Ó Senhor, ó Senhor Deus, misericordioso e piedoso, tardio em irar-se e grande em beneficência e verdade" (Ferreira de Almeida).

A leitura não termina, apenas pode ser interrompida ou retomada.

Moacir Amâncio é professor de Língua e Literatura Hebraica da USP, autor, entre outros livros, de "Óbvio" (poemas, Travessa dos Editores)

\begin{abstract}
In this article, the reading of the Bible in Hebrew is discussed as well the difficulties of translating the Leitwörter, "those series of similar or formally linked words" which Rosenzweig took as a kind of cue to understand the meaning of the text.
\end{abstract}

Key-words: Bible, translation, feminism

126 Moacir Amâncio - A Fulguração de Ana 